\title{
RECONHECIMENTO DO NOTÓRIO SABER E A INCLUSÃO EXCLUDENTE DO PROFESSOR NA EDUCAÇÃO BÁSICA: QUAL O LUGAR DA UNIVERSIDADE NA FORMAÇÃO?
}

\author{
RECONOCIMIENTO DEL NOTORIO SABER Y LA INCLUSIÓN \\ EXCLUYENTE DEL PROFESOR EN LA EDUCACIÓN BÁSICA: ¿QUÉ ES EL \\ LUGAR DE LA UNIVERSIDAD EN LA FORMACIÓN DOCENTE?
}

CERTIFICATION OF NOTORIOUS KNOWLEDGE AND THE EXCLUSIONARY CHARACTER OF TEACHERS INCLUSION IN BASIC EDUCATION: WHAT IS THE LOCUS OF UNIVERSITY IN TEACHER TRAINING?

RESUMO: O artigo resulta da investigação sobre o "reconhecimento do notório saber" como requisito para o exercício da docência na educação básica, previsto na Lei $\mathrm{N}^{\mathrm{o}}$ 13.415/2017. A hipótese é que tal iniciativa é decorrência das políticas de formação docente implementadas a partir da Lei 9.394/1996, que abriu possibilidades para a formação em espaços outros que não a educação superior, como lócus privilegiado da formação. O objetivo é compreender o processo de construção da ideia de "reconhecimento de notório saber" como requisito para a docência no decurso das políticas de formação para o trabalho docente na educação básica, articuladas ao modelo de gestão educacional de caráter gerencialista. Trata-se de uma pesquisa básica, de análise qualitativa, de caráter explicativo que se insere na categoria de pesquisa bibliográfica. A análise parte da definição de formação prática e teórica para o trabalho docente para indicar a educação superior como espaço apropriado e coerente com tal formação e, por isso, capaz de extinguir o caráter da inclusão excludente do professor na educação básica por meio do "reconhecimento do notório saber". Os resultados apontam que o "reconhecimento do notório saber" como requisito para a docência contribui para a desprofissionalização do trabalho docente, ao fundamentar-se no argumento do "aprender a aprender" como caminho para indivíduos autogerirem sua própria formação e atualização profissional.

PALAVRAS-CHAVE: Formação docente. Notório saber. Educação superior. Certificação de competências.

\footnotetext{
${ }^{1}$ Trata-se de uma versão revisada e ampliada do trabalho apresentado no XXV Seminário Nacional da Rede.

${ }^{2}$ Universitas/BR.Universidade Federal do Rio de Janeiro (UFRJ), Rio de Janeiro - RJ - Brasil. Professora Adjunta do Departamento de Administração Educacional da Faculdade de Educação. Docente do Programa de Pós-graduação Strictu Senso Políticas Públicas em Direitos Humanos (PPDH/UFRJ). Membro do Coletivo de Estudos e Pesquisas em Marxismo e Educação (COLEMARX/UFRJ) e do Grupo de Pesquisa Sobre Trabalho, Política e Sociedade (GTPS/UFRRJ).E-mail: jussara0712@gmail.com.
} 
RESUMEN: El trabajo resulta de la investigación sobre el reconocimiento del "notorio saber" como requisito para el ejercicio de la docencia en la educación básica, previsto en la Ley $N^{o}$ 13.415/2017. La hipótesis es que tal iniciativa es consecuencia de las políticas de formación docente implementadas a partir de la Ley 9.394/1996, la cual abre posibilidades para la formación en espacios distintos a la educación superior como locus privilegiado de la formación. El objetivo es comprender el proceso de construcción de la idea de reconocimiento del notorio saber cómo requisito para la docencia en el curso de las políticas de formación para el trabajo docente en la educación básica articuladas al modelo de gestión educativa de carácter gerencialista. Se trata de una investigación básica, de análisis cualitativo, de carácter explicativo, que se inserta en la categoría de una investigación bibliográfica. El análisis parte de la definición de formación práctica y teórica para el trabajo docente para indicar la educación superior como espacio apropiado y coherente con tal formación y, por lo tanto, capaz de extinguir el carácter de la inclusión excluyente del profesor en la educación básica por medio del reconocimiento del Notorio saber. El análisis apunta que el reconocimiento del "notorio saber" como requisito para la docencia contribuye a la desprofesionalización del trabajo docente, al fundamentarse en el argumento del "aprender a aprender" como camino para individuos autogerir su propia formación y actualización profesional.

PALABRAS CLAVE: Formación docente. Notorio saber. Educación universitaria. Certificación de competencias.

ABSTRACT: The article results from the research on the "certification of notorious knowledge" as a requirement for teaching in basic education, provided for in Law $n^{o}$ 13.415/2017. The hypothesis is that this initiative results of the training policies for the teacher's work implemented as of Law $n^{\circ}$ 9.394/1996, which opened possibilities for teacher's training in spaces other than higher education, as a privileged locus of teacher's training. The objective is to understand the process of constructing the idea of " certification of notorious knowledge" as a requirement for teaching in the development of the training policies for the teacher's work in basic education, articulated to the new management model of educational. It is a basic research, of qualitative analysis, of explanatory character that falls within the category of bibliographic research. The analysis is based on the idea from the definition of the higher education as an appropriate and coherent space with such teacher's training and, therefore, able to extinguish the exclusionary character of the teacher's inclusion in basic education through the "certification of notorious knowledge". The results point out that the "certification of notorious knowledge" as a requirement for teaching contributes to the deprofessionalization of teacher's work, as it is based on the "learn to learn" argument, as a way for individuals to generate their own professional training and updating.

KEYWORDS: Teacher training. Notorious knowledge. Higher education. Certification of competencies.

\section{Introdução}


As políticas de formação para o trabalho docente nos últimos anos de reestruturação da sociedade capitalista fazem parte do processo de mundialização das políticas educacionais, seguindo à lógica da política e da economia defendida pelos organismos internacionais como o Banco Mundial e a Organização das Nações Unidas para a Educação, a Ciência e a Cultura (UNESCO), por exemplo. Sendo assim, o que está em pauta é a certificação de competências que podem ser por meio da formação inicial, da formação em serviço ou, ainda, por meio de processos avaliativos do trabalho docente.

Prevalece a ideia de que a educação para o século XXI deve ser aquela que considera a "sociedade em redes" para garantir a "globalização" para além das fronteiras institucionais, ao mesmo tempo em que busca romper com a educação tida como tradicional para tornar senso comum a ideia da "educação ao longo da vida" possibilitada, principalmente, pelas Novas Tecnologias da Informação e da Comunicação (NTIC).

O interesse das autoridades educacionais, dos indivíduos, dos empresários e da sociedade em geral pela certificação faz parte de um aspecto mais amplo da formação do trabalhador e está ligado diretamente ao papel econômico da certificação na sociedade capitalista. Esta perspectiva pauta-se na Teoria do Capital Humano ${ }^{3}$, segundo a qual a educação confere um valor adicional à força de trabalho do indivíduo, no mercado de trabalho, ao mesmo tempo em que a certificação assume a função do controle da qualidade do trabalho.

No Brasil, tais ideias se materializaram a partir da contrarreforma ${ }^{4}$ do Estado de 1995 com a "Nova Gestão Pública" fundamentada no gerencialismo. No que se refere à educação, isso implicou em uma nova forma de gestão do trabalho e do conhecimento docente, possibilitado pela venda da mercadoria "educação", atingindo diretamente a formação e o trabalho docente. A Lei 9.394/96, além de reproduzir tais pressupostos, autorizou que a formação para o trabalho docente na educação básica fosse feita em

\footnotetext{
3 A Teoria do Capital Humano foi desenvolvia por Schultz (1973) e trata a educação como um componente da produção, ou seja, a educação como produtora da capacidade de trabalho ligada ao desenvolvimento social e econômico.

${ }^{4}$ Para Fernandes (2006), a burguesia, na ânsia de se manter como classe dominante, implementa a contrarrevolução burguesa e contrarreforma, ou seja, a burguesia em um determinado momento histórico, realiza uma forma contrarrevolucionária para manter o status quo que impede a verdadeira revolução, pautada nos interesses da classe trabalhadora. Nesse sentido, entendemos contrarreforma do Estado brasileiro como sua capacidade de ampliação, eficiência e regulação, orientada pelos organismos internacionais. No caso da educação a administração escolar foi modificada, com a introdução de novas formas de regulação sobre o trabalho, sob a justificativa de que o novo modelo gerencial ampliaria a eficiência e qualidade do serviço público.
} 
espaços outros, negligenciando assim, a universidade como lócus privilegiado da formação. Como consequência, está em pauta o "reconhecimento do notório saber" como requisito para o exercício da docência na educação básica, como prevê a Lei $\mathrm{N}^{\mathrm{o}}$ 13.415/2017 que, além de descartar a formação docente da universidade, abre possibilidades para que tal formação seja feita pela iniciativa privada fortalecendo, dessa forma, a formação fragmentada e aligeirada pautada na prática em detrimento da teoria.

Diante disso objetivamos compreender o processo de construção da ideia de "reconhecimento de notório saber" como requisito para a docência na educação básica por meio das políticas de formação para o trabalho docente, implementadas em tempos da gestão educacional de caráter gerencialista.

A metodologia pauta-se no materialismo histórico e dialético cuja análise concreta da realidade parte da aparência com vistas a alcançar a essência do fenômeno observado (KOSIK, 1969), por meio de seus múltiplos aspectos. O artigo resulta de uma análise qualitativa, fundamentado em uma pesquisa básica, de caráter explicativo que se insere na categoria de pesquisa bibliográfica por meio de fontes primárias e secundárias. A análise parte da definição de formação prática e teórica para o trabalho docente para indicar a educação superior como espaço apropriado e coerente com tal formação e, por isso, capaz de suprimir o caráter da inclusão excludente do professor na educação básica por meio do reconhecimento do notório saber.

Os resultados apontam que o "reconhecimento do notório saber" como requisito para a docência contribui para a desprofissionalização do trabalho docente, ao fundamentar-se no argumento do "aprender a aprender" como possibilidade para indivíduos autogerirem sua própria formação e atualização profissional. Daí, concluímos que a formação em nível superior deve ser o lócus privilegiado de formação para o trabalho docente na educação básica, por possibilitar, dentre outras coisas, uma formação de caráter omnilateral ${ }^{5}$, capaz de contribuir para a formação do sujeito emancipado e comprometido com a educação da classe trabalhadora.

\footnotetext{
5 A educação pautada nos princípios da omnilateralidade forma o indivíduo em todas as dimensões humanas, sejam elas intelectivas, biopsíquicas, lúdicas, afetivas ou quaisquer outras, imprescindíveis à formação de um indivíduo crítico, autônomo, livre etc. (FRIGOTTO, 2001), mas que não pode ser posta em prática na visão limitada do mercado. O começo da escola unitária significa, mais de qualquer outra coisa, "o início de novas relações entre trabalho intelectual e trabalho industrial não apenas na escola, mas em toda a vida social. O princípio unitário, por isso, refletir-se-á em todos os organismos de cultura, transformando-os e emprestando-lhes um novo conteúdo" (GRAMSCI, 1991, p. 125).
} 


\section{Políticas de formação para o trabalho docente na educação básica}

O final do século XX foi marcado por significativa participação dos movimentos sociais com vistas à educação para a transformação social. A Constituição de 1988, influenciada por este movimento, assegurou a educação como direito social que deveria atingir a todos constituindo-se, portanto, em dever do Estado e da família (BRASIL.CASA CIVIL, 1988). Diferente do que propunha a Constituição, a Lei 9.394/96, que estabelece as Diretrizes e Bases da Educação Nacional (LDB), aponta que a educação é dever da Família e do Estado (Art. $2^{\circ}$ ) não deixando dúvidas quanto ao processo de desresponsabilização do Estado, em parte, pela educação pública. No que se refere ao trabalho docente, foi colocado em pauta a necessidade de formação para o trabalho docente em suas múltiplas dimensões (Título VI, Art. 62).

A mesma Lei ressaltou no Art. 63 que cabe aos institutos superiores de educação promover o aperfeiçoamento profissional e continuado (Inciso III) ao mesmo tempo em que estabeleceu no Art. 61, inciso I, a "associação entre teorias e práticas, inclusive mediante a capacitação em serviço" (Inciso I). Observa-se que a LDB adotou as nomenclaturas "formação de profissionais da educação" (Art. 61) e "formação de docentes" (Art. 62) para designar o que aqui chamaremos de "formação para o trabalho docente".

No ano de 2002, o Conselho Nacional de Educação (CNE) institui as Diretrizes Curriculares Nacionais para a Formação de Professores da Educação Básica, em nível superior, curso de licenciatura, de graduação plena (BRASIL.MEC.CNE, 2002), onde se corrobora a articulação entre os termos "formação profissional" e/ou o "exercício profissional" ligado à formação.

O Decreto 6.755/2009 instituiu a Política Nacional de Formação de Profissionais do Magistério da Educação Básica "com a finalidade de organizar, em regime de colaboração entre a União, os Estados, o Distrito Federal e os Municípios, a formação inicial e continuada dos profissionais do magistério para as redes públicas da educação básica" (BRASIL.CASA CIVIL, 2009), destacando a responsabilidade do docente no "processo educativo da escola e de sua valorização profissional," bem como sua "formação continuada" (Art. $2^{\circ}$, inciso VIII). No que se refere à formação inicial o Decreto prevê "a equidade no acesso à formação inicial e continuada" (inciso IX) e a "articulação entre formação inicial e formação continuada" (inciso X). Observamos que 
os termos formação e profissionalização se apresentam em alguns momentos como sinônimos embora em outros sejam complementares.

Em conformidade com as alterações relativas à formação para trabalho docente ainda no mesmo ano, o Decreto $N^{\circ}$ 12.014/2009 altera o Art. 61 da LBD objetivando distinguir as categorias destes trabalhadores que devem ser considerados profissionais da educação básica.

Neste aspecto, sintetizamos que a exigência para a realização do trabalho docente na educação básica far-se-á mediante à formação em cursos de nível médio na modalidade normal ou superior reconhecidos. A formação dos demais trabalhadores da educação para a “administração, planejamento, inspeção supervisão e orientação educacional para a educação básica”, conforme Art. 64 da LDB (BRASIL, 1996), será feita em cursos de Pedagogia podendo ser reconhecidos, ainda, os títulos obtidos em cursos de Pós-Graduação.

A Resolução No 04/2010, que define as Diretrizes Curriculares Nacionais Gerais para a Educação Básica, especifica no capítulo IV, Art. 56, que a fundamentação da ação docente, bem como os programas de formação inicial e continuada dos profissionais da educação, exigem um método de aprendizagem com vistas a formar o perfil do docente da educação básica. Neste aspecto, o $\S 1^{\circ}$ salienta que as instituições formadoras deverão incluir em seus currículos e programas elementos que visem este fim.

A ideia de formação inicial e continuada do docente, de acordo com o Art. 57 (BRASIL.MEC.CNE. CEB, 2010) atrela-se aos princípios definidos para a educação nacional incluindo a valorização do profissional da educação com extensão para a valorização da escola com qualidade no campo da gestão, do ensino, da cultura etc.

A Resolução $N^{o}$ 04/2010 indica que a formação para o trabalho docente na educação básica assume uma perspectiva de formação global deste trabalhador. De acordo com a legislação, esse trabalhador deverá exercer suas atividades laborais segundo as exigências do mercado de trabalho. Dele se exige não apenas a atualização, mas sobretudo, a disponibilidade para a elaboração de matérias didáticos, planejamento pedagógico, participação na comunidade escolar etc. (MACEDO, 2011). Ou seja, espera-se do trabalhador docente atividades laborais que extrapolam o campo da sua atuação docente e para as quais o curso de formação não o prepara.

Apesar do excessivo número de regulamentação da formação para o trabalho docente no Brasil evidencia-se, cada vez mais, a migração de outros profissionais que 
em época de desemprego estrutural do capitalismo (ANTUNES, 2003) migram, dos mais diferentes campos, para a área da educação, como forma de complementação de renda, mas que não assumirão compromisso com a carreira docente.

Tendo em vista que a identidade profissional da categoria docente é definida, dentre outras coisas, pela formação inicial e continua, a Resolução No 02/1997 coloca em xeque esta premissa quando define que:

Art. $1^{\circ}$ A formação de docentes no nível superior para as disciplinas que integram as quatro séries finais do ensino fundamental, o ensino médio e a educação profissional em nível médio, será feita em cursos regulares de licenciatura, em cursos regulares para portadores de diplomas de educação superior e, bem assim, em programas especiais de formação pedagógica estabelecidos por esta Resolução (BRASIL, 1997).

Por meio de uma operação quase embaraçada, farmacêuticos foram transformados em docentes de química, médicos em docentes de biologia, engenheiros em docentes de matemática. $\mathrm{O}$ resultado foi o aumento de trabalhadores docentes formados em cursos aligeirados de complementação pedagógica com certificação aos diplomas de licenciatura plena expedidos por diferentes Instituições de Ensino Superior (IES), muitas delas recém-criadas, sem nenhuma idoneidade para o que se propunham.

Evidencia-se com isso, um tipo de inclusão excludente do professor na educação básica uma vez que, no atual patamar de desenvolvimento do capitalismo, os novos espaços de formação para o trabalho docente se mostram incapazes de estabelecer um processo de formação e de conhecimento socialmente elaborado que contribua para a elevação do indivíduo como agente de transformação social. O espaço escolar tem se consubstanciado em um ambiente de permanência de estudantes e, além de preparar para as exigências da produção do mundo capitalista,

[...] assume também as exigências da ordem social desenvolvida nos processos de trabalho, tais como disciplina, exatidão, submissão física, técnica e moral, cumprimento estrito dos deveres, pontualidade contenção corporal e efetiva. Ela assume os deveres impostos pela produção, através dos mecanismos do Estado, e relega a segundo plano, sob mil artifícios ideológicos, o direito à educação que fundamenta as demandas da sociedade civil (CIAVATTA, 2002 p. 128). 
O princípio da inclusão excludente está presente na implementação de propostas educacionais arquitetadas ao modo aligeirado de formação que conta com o consentimento da classe trabalhadora, a que Alves (2000) bem denominou como forma de "captura da subjetividade operária"6. Assim, os trabalhadores docentes de novo tipo, esperam adquirir novas formas de sobrevivência a partir da certificação escolar ou, ainda, atender às demandas do capital que busca, com esta prática, superar a crise de suas taxas de lucro, provocadas pelas cíclicas crises do sistema capitalista de produção.

Diante disso, cabem alguns questionamentos: este profissional pode ser considerado um profissional da educação? Além da formação aligeirada, quais outros requisitos foram levados em conta? Para a realização do trabalho docente na educação básica exige-se a experiência relacionada aos conteúdos da matéria a ser ensinada ou a prática docente? Qual o lugar da formação teórica destes trabalhadores? Com novos espaços de formação para o trabalho docente e o reconhecimento do notório saber para a realização do trabalho docente na educação básica, qual o papel dos cursos de licenciaturas nas universidades?

As possíveis respostas a tais questionamentos relacionam-se diretamente com as diversas/novas atribuições dos sistemas educativos, aos modelos de gestão, aos programas de formação para o trabalho docente, a valorização, a precarização do trabalho e ao papel social docente cujas ideias basilares encontram-se na pósmodernidade, respaldadas pela lógica da "sociedade do conhecimento" onde avaliação e certificação de competências conformam o trabalhador de novo tipo (MACEDO, 2011). Além disso, já demonstramos que existe uma relação entre o "novo modelo de gestão do trabalho e a intensificação dos processos de desprofissionalização e proletarização do trabalho docente" (MACEDO; LAMOSA, 2015, p. 133).

\section{Reconhecimento de notório saber e a desprofissionalização docente}

A ideia de uma "sociedade pós-capitalista" ou "capitalismo informacional" supõe a passagem para a "sociedade do conhecimento", que é descrita por Drucker (1994) como aquela que substituirá a era do capitalismo que se liga à noção de NaçãoEstado e será substituída pela lógica do megaestado. O conhecimento será o principal

${ }^{6}$ Souza (2015) se utiliza dessa categoria para explicar o processo de precarização do trabalho docente nos Institutos Federais de Educação, Ciência e Tecnologia - conhecidos como "Institutos Federais" alegando que os trabalhadores docentes não têm sido capazes de, no "cotidiano marcado pelo pragmatismo e pela visão imediata, carente de reflexões mais profundas, [...] subsidiar uma crítica mais qualificada sobre a realidade vivida" (p. 73). 
recurso, que trará como consequência grupos sociais mais importantes constituídos por "trabalhadores do conhecimento", que serão formados para dominarem as Novas Tecnologias da Informação e da Comunicação (NTIC) e, com isso aumentar a produtividade.

A revolução gerencial, para Drucker, está ligada à aquisição de conhecimento por parte do indivíduo (DRUCKER, 1995) e a renda está relacionada à um diploma formal que passa a ser a certificação do conhecimento adquirido. Este conhecimento só pode ser sistematizado em uma escola, que terá a função de formar profissionais do conhecimento que saibam dominar as NTIC. Não se trata, apenas, de uma gestão de negócios, mas, sobretudo, de um órgão genérico da organização moderna. Por isso, os setores não empresariais necessitam da gestão bem mais do que os negócios (DRUCKER, 1995). A gerência é a função genérica de todas as organizações (escolas, hospitais, associações, sindicatos, empresas etc.). O que define se uma gerência é eficaz é a aplicação do conhecimento ao conhecimento.

Não se trata de um conhecimento tradicional e genérico, e sim aquele que forma o sujeito especializado. Este deve expressar, na ação, sua capacidade específica, já que o conhecimento é a informação eficaz na ação, focalizando os resultados na sociedade, na economia, no avanço do conhecimento. Por isso, o valor da experiência, do aprendizado, do treinamento, ao invés da instrução escolar (DRUCKER, 1994). O sistema de ensino necessário à "sociedade do conhecimento" é aquele que leva em conta as novas especificações. Neste caso, “o ensino não pode mais ser um monopólio das escolas (DRUCKER, 1994, p. 154).

A educação centra-se na ideia de "educação ao longo da vida", que trabalhe com as NTIC, que se preocupe com o desempenho dos alunos, que veja no professor um líder com domínio das tecnologias, que valorize o aprendizado individual, que proporcione ao aluno a capacidade de aprender a aprender ${ }^{7}$, que retome as bases da pedagogia do desejo, que esteja preocupada com o rendimento do aluno, e que este seja medido por meio da avaliação. O docente torna-se gerente de si mesmo enquanto o gestor escolar assume o papel de controlador do trabalho docente (SHIROMA, 2004). Para este tipo de trabalhador docente a formação inicial se torna menos importante do

7 Os quatro pilares da educação necessários para a educação do século XXI, definidos no Relatório Jacques Delors (Educação: um tesouro a descobrir) de 1996 são: aprender a conhecer, aprender a fazer, aprender a viver juntos e aprender a ser (DELORS, 2001, p. 90). Contudo, a área da administração tem acrescentado um quinto pilar, aprender a empreender, com foco no empreendedorismo educacional (ACIC, 2017). 
que a formação continuada. A base deste discurso está na "avaliação e certificação de competências e qualificações profissionais" tema defendido pela UNESCO que prevê, dentre outras coisas, que o conhecimento que é adquirido no trabalho deverá ser "objeto de avaliação, reconhecimento e certificação para prosseguir ou concluir os estudos" (BERTRAND, 2005, p. 7).

No caso brasileiro esta sugestão/imposição se materializou no Título I, Art. $1^{\circ}$, da Lei 9.394/96, quando define que: "A educação abrange os processos formativos que se desenvolvem na vida familiar, na convivência humana, no trabalho, nas instituições de ensino e pesquisa, nos movimentos sociais e organizações da sociedade civil e nas manifestações culturais" (BRASIL, 1996). A educação para o século XXI deve considerar a "sociedade do conhecimento" para garantir a "globalização" para além das fronteiras institucionais, ao mesmo tempo em que rompe com a educação tradicional e se constitui em uma "educação ao longo da vida", expressão presente no relatório da UNESCO (DELORS, 2001) e de outros organismos e acordos internacionais. A respeito da Lei 9.394/96, a UNESCO a elogia, fazendo referência ao Art. $1^{\circ}, \S 1^{\circ}$, quando "disciplina a educação escolar, que se desenvolve, predominantemente, por meio de ensino em instituições próprias" (BRASIL, 1996, p. 10).

Segundo Bertrand (2005), o interesse pela "avaliação e certificação de competências e qualificações profissionais" pode ser explicado, dentre outras coisas pela "vontade de avaliar a eficácia de sistemas dispendiosos de formação; de fixar-lhes objetivos que respondam às novas demandas do mercado de trabalho; de manter certo controle como contrapartida à tendência para descentralização; necessidade de adaptação das exigências da formação permanente" (BERTRAND, 2005, p. 11).

Contudo, Bertrand (2005) deixa claro que, por conta da ideia de "educação ao longo da vida", a certificação pode ser apenas uma etapa da formação do indivíduo. Ela é, por isso, um tema que instiga o interesse dos empresários, pois se relaciona diretamente com o mercado de trabalho. Neste caso, a certificação ajuda no reconhecimento das qualidades, dos conhecimentos e das habilidades (savoir-faire) dos indivíduos, possíveis contratados.

No que se refere ao trabalho docente, os organismos internacionais ${ }^{8}$ apontam a necessidade de uma formação prática em detrimento da teoria, alegando, que a

${ }^{8}$ Os organismos internacionais à que nos referimos são: Banco Mundial (BM), Organização das Nações Unidas para a Educação, a Ciência e a Cultura (UNESCO) e Organização para a Cooperação e Desenvolvimento Econômico (OCDE). Em trabalho anterior (MACEDO, 2011), concluímos que mesmo 
formação oferecida pelas IES além de custosas e demoradas, não formam para a realidade das escolas. Soma-se a este discurso a afirmação de que a escola é culpada pelo fracasso do estudante a medida que se torna evidente o distanciamento entre os conteúdos ensinados e as novas demandas do mundo do trabalho e da produção. Todo este discurso é evidenciado não apenas nos documentos oficiais dos organismos internacionais como também nos documentos do Ministério da Educação (MEC) direcionados à "formação do professor". Evidencia-se a culpabilização do docente por meio do discurso que os "os professores são despreparados para trabalhar com o aluno da escola pública e que se sentem abandonados e sem assistência para enfrentar tão difícil tarefa, para a qual não receberam formação adequada” (MELLO, 2005, p. 60). Por isso, deverá ser substituído por professores que deverão ser "atraídos" e “recrutados" de outras áreas do conhecimento (OCDE, 2006).

Eis a gênesis do reconhecimento do notório saber para a realização do trabalho docente na educação básica. No Brasil estas ideias foram disseminadas por intelectuais do capital como Guiomar Namo de Mello que reafirma a necessidade de reformular as bases teóricas e práticas da "formação do professor", defendendo que se todo professor em formação cumpriu a educação básica, espera-se dele que tenha "constituído conhecimentos, competências e habilidades básicas para ser um cidadão produtivo" (MELLO, 2000, p. 105).

$\mathrm{Na}$ defesa de um "sistema nacional de certificação de competências para professores" Mello (2000, p. 108) afirma a necessidade da existência de "critérios de autorização dos cursos e de avaliação dos formandos e dos professores já em exercício". Trata-se, segundo ela, de uma política nacional que deve ser de responsabilidade da União, mas com a participação de diferentes interessados. Para isso, dois pontos de consenso são necessários. O primeiro é estabelecer o consenso acerca da formação de professores e, o segundo deverá ser "o credenciamento de cursos e certificação de competências" (MELLO, 2000, p. 108).

A partir dos anos de 1990, tais consensos atingiram diretamente o trabalhador docente em vários aspectos, mas especificamente no que se refere à política de certificação que limita o trabalho docente a uma ação educativa de caráter técnico que se aprofunda durante a década com marcas do gerencialismo. Os conteúdos dos cursos de formação são pensados sob a forma de competências a partir apenas do savoir-faire 
de determinada tarefa fazendo com que a formação seja direcionada pelas necessidades do mundo do trabalho de soluções cientificistas e imediatas para a formação com base nas NTIC.

Neste complexo que envolve a formação para o trabalho docente, aparece a possibilidade do reconhecimento do "notório saber" que em sua significação pode ser considerada uma medida excepcional para o reconhecimento público de conhecimento e/ou erudição, mas que não pode se constituir em atalho para a formação para o trabalho docente. Contudo, a Medida Provisória No 746/2016 apresenta este atalho na formação para o trabalho docente para as escolas de nível médio em tempo integral, quando considera, no Art. 61, inciso III que "trabalhadores em educação [são os], portadores de diploma de curso técnico ou superior em área pedagógica ou afim”. Além disso, reconhece no inciso $\mathrm{V}$, "profissionais com notório saber reconhecido pelos respectivos sistemas de ensino para ministrar conteúdos de áreas afins à sua formação". Apesar da indicação, a MP não prevê como será e por quais meios se dará a certificação.

A Lei $N^{o} 13.415 / 2017$ que dentre outras coisas, institui a Política de Fomento à Implementação de Escolas de Ensino Médio em Tempo Integral, considera no Art. 61:

IV- profissionais com notório saber reconhecido pelos respectivos sistemas de ensino, para ministrar conteúdos de áreas afins à sua formação ou experiência profissional, atestados por titulação específica ou prática de ensino em unidades educacionais da rede pública ou privada ou das corporações privadas em que tenham atuado [...] (BRASIL, 2017).

Como a MP No 746/2016, a Lei $\mathrm{N}^{\circ} 13.415 / 2017$ também não prevê as formas de certificação do "notório saber", mas avança no sentido de indicar as instituições de educação com "notório reconhecimento" que poderão oferecer cursos de nível médio se cumpridas as exigências curriculares deste grau de ensino. De acordo com o $§ 11$ da Lei, os sistemas de ensino "poderão reconhecer competências e firmar convênios com instituições de educação a distância [...] (BRASIL, 2017).

Não resta dúvida de que a proposta de Mello (2000), no que se refere à política nacional de formação de professores bem se encaixa nesta lógica de criação do consenso em torno do credenciamento de cursos e certificação de competências. Primeiro, porque a autora defende o rejuvenescimento do Curso Normal de Nível Médio para formar "professor polivalente", segundo porque a formação para o trabalho docente, nestes espaços, poderá ser feita de modo aligeirado com auxílio das NTIC. 
Uma experiência que se fortalece no Brasil voltada para a formação para o trabalho docente é a Rede "Ensina Brasil" "que se propõe a formar um "ensina ${ }^{10 "}$ em apenas cinco semanas. A busca é por "jovens talentos de diversas carreiras que almejem trabalhar com um propósito e queiram direcionar seus talentos e esforços para os problemas mais complexos do país” (ENSINA BRASIL, 2017). Durante dois anos no programa "Ensina Brasil", o jovem se submeterá a uma formação contínua que proporcionará uma "experiência incomparável de estar na sala de aula".

Uma vez selecionados e depois de um "treinamento" de cinco semanas onde são passadas as teorias necessárias ao exercício da "profissão de professor" o jovem é promovido à "professor temporário" que será fornecido aos "governos-parceiros" com um salário inicial ao da carreira docente. Os dois anos em sala de aula são vistos como um tipo de "treinamento em serviço".

"Ensina Brasil” é uma empresa financiada pela Fundação Lemann e Itaú Social, dentre outas, com relações estreitas com a Teach For $A l l^{11}$ cuja função é recrutar e preparar professores temporários para diferentes governos. Lamentavelmente, parece ser esta a mais recente ofensiva gerencialista de formação para o trabalho docente na educação básica com participação dos empresários. A defesa é de uma formação centrada na prática em detrimento da formação teórica o que parece ser uma nova estratégia de formação para o trabalho docente.

O que apontamos aqui como "novidade", são na verdade, indicativos dos organismos internacionais a partir do ano de 1990 para a formação e o trabalho docente (MACEDO, 2011). No Brasil, isso tem se materializado por meio da gestão gerencialista da educação, que dentre outras coisas, promove a desprofissionalização docente. A profissionalização defendida pelos intelectuais do capital refere-se a um tipo de desprofissionalização do caráter específico da profissão docente marcado pela fragmentação e aligeiramento na formação inicial e contínua com base nos conhecimentos tácitos, ao mesmo tempo retira do docente seu protagonismo na produção do conhecimento e a perda de autonomia para conduzir o processo ensinoaprendizagem.

${ }^{9}$ São parceiros da Rede "Ensina Brasil": Teach For All, Federação das Empresas Juniores do Estado de São Paulo (FEJESP), Fundação Estudar, Brasil Júnior e AIESEC.

10 Nomenclatura usada pela Rede "Ensina Brasil" para designar "professor". Já demonstramos (MACEDO, 2011) que o termo professor tem sido substituído, na "sociedade do conhecimento" por "monitor", "tutor", "oficineiro" etc.

${ }^{11}$ É uma Organização Não-Governamental americana que oferece uma plataforma global que permite aos sócios da rede conectar-se e aprender uns com os outros. O objetivo central é formar professores em seis semanas por meio de financiamento oriundo do setor privado (TEACH FOR ALL, 2017, texto em html). 


\section{Formação docente para educação básica e o lugar da universidade}

Pensar a formação para o trabalho docente na educação básica em nível superior requer romper com o tipo de formação que está inserida no contexto da "sociedade do conhecimento", das novas formas de "globalização" da economia e da flexibilização do trabalho. Neste aspecto a formação enfatiza competências e habilidades como elementos que contribuem para que este trabalhador, na prática, repasse aos estudantes os princípios da sociedade capitalista, ao mesmo tempo em que nega qualquer possibilidade de mudança. A formação docente alternativa deve se pautar pelo modelo de "formação de um intelectual de novo tipo, adequado ao desenvolvimento das formas reais da vida contemporânea, capacitado técnica e politicamente para decodificar os avanços verificados no mundo do trabalho e na sociabilidade no atual patamar de desenvolvimento do capital" (MACEDO, 2002, p. 13). Esse intelectual deve se comprometer com as mudanças da sociedade e buscar, nos princípios da educação socialista (MÉSZÁROS, 2008), elementos necessários para a formação do indivíduo emancipado.

Diferente do "sistema nacional de certificação de competências para professores" (MELLO, 2000), a ideia de "base comum nacional de formação" (ANFOPE, 2008, p.3) seria a alternativa "à concepção de currículo mínimo, [como] o instrumento que marca a resistência às políticas de aligeiramento, fragilização e degradação da formação e da profissão do magistério" (FREITAS, 2000, p. 19). Tal concepção tomaria à docência como elemento fundamento da identidade do educador. Os princípios norteadores são: sólida formação teórica e interdisciplinar; unidade entre teoria e pratica; gestão democrática; compromisso social e ético do trabalhador da educação; trabalho coletivo e interdisciplinar; formação inicial articulada à formação continuada; e, avaliação permanente dos cursos de formação.

Tais princípios sempre estiveram ligados à defesa de que as universidades, por meio de seus cursos de Pedagogia, se constituíssem no espaço privilegiado de "[...] formação docente dos educadores para atuar na Educação Básica: na Educação Infantil e nos anos iniciais do Ensino Fundamental" (ANPED/ANOPE/CEDES, 2004, p. 1).

Várias críticas foram feitas na década de 1990 referentes aos cursos de formação docente fora da universidade. Otranto (1999), por exemplo, ao analisar o Parecer $\mathrm{N}^{\mathrm{o}}$ 115/99, que dispunha sobre as Diretrizes Gerais para os Institutos Superiores de Educação (ISE), aprovado no ano de 1999 pelo CNE, conclui que o "sistema 
universitário brasileiro não precisa criar uma nova instituição para alcançar os objetivos de proporcionar formação inicial, complementar e continuada aos professores da educação básica" (OTRANTO, 1999, p. 78).

Na mesma linha de raciocínio, não é demais reafirmar a importância do curso de Pedagogia, na maioria das IES, que, desde meados dos anos de 1980, “constitui-se como um curso de graduação plena, licenciatura e bacharelado, com projeto pedagógico próprio, responsável pela formação de profissionais para a educação básica, eliminando a fragmentação das antigas habilitações, e possibilitando sua inserção em outros campos profissionais (FREITAS, 2000, p. 26).

Foram estes alguns dos subsídios que motivaram o movimento dos educadores a discutir a elaboração das Diretrizes Curriculares do Curso de Pedagogia, que teve seu marco importante, no ano de 1999, quando uma Comissão de Especialistas em Pedagogia foi constituída para elaborar as diretrizes do curso. Esse movimento desencadeou "um amplo processo de discussão em nível nacional, ouvindo as IES, suas coordenações de curso e as entidades da área" (ANPED/ANOPE/CEDES, 2004, p. 8). No mesmo ano, foi encaminhado ao CNE o documento das Diretrizes Curriculares elaborado por essa Comissão, mas que, infelizmente, não chegou a ser apreciado, já que a Secretaria de Educação Superior (SESU) e a Secretaria de Educação Fundamental (SEF) não o enviaram ao CNE, como tentativa de boicote explícito e um desejo de pôr em seu lugar as diretrizes do Curso Normal Superior que estavam prestes a ser regulamentadas, naquela época.

Entre 1999 e 2005, várias foram as iniciativas do MEC em relação às licenciaturas e ao curso de Pedagogia. Porém, elas significaram para algumas instituições compromissadas com esta formação mais um transtorno do que auxiliaram os cursos em suas definições, principalmente os cursos de Pedagogia. Isso teve como resultado a expansão destes, principalmente em IES privadas que não apresentavam nenhum compromisso com a formação docente (ANPED/ANOPE/CEDES, 2004).

Talvez essa tenha sido a estratégia do governo brasileiro para abrir espaços para a criação de diferentes cursos de formação para o trabalho docente na educação básica, em cumprimento às exigências dos organismos internacionais, o que se constitui na segunda fase da reforma educacional brasileira (SHIROMA, 2004).

A partir do início do século XXI, sob o discurso da "sociedade do conhecimento", a formação em nível superior passou a se constituir num elemento indispensável à formação docente. O papel da Educação Superior, na sociedade, 
expressa a possibilidade de "educação ao longo da vida" para o melhor domínio das NTIC.

Se faz necessária a execução do projeto político pedagógico e do currículo, considerando a necessidade de reconhecimento de que "não existe apenas uma 'alternativa' de formação e sim inúmeras que vêm sendo construídas nas IES e que não servem de 'modelo', mas de oportunidade para melhor efetivação de outros cursos onde quer que se localizem" (ANOPE/ANPED/CEDES, 2004, p. 8), defende a ANFOPE há décadas. Continua em voga a defesa de um sistema nacional de formação em que sejam organizadas, organicamente as ações das diferentes IES, dos sistemas de ensino e do MEC.

O curso de Pedagogia forma parte da intelectualidade pedagógica do país. Se tomamos o pedagogo como intelectual, a sua formação deverá proporcionar conhecimento de sua realidade local, nacional e internacional, e isso provocará o desdobramento dos seguintes aspectos: $a$ ) formação histórica; $b$ )formação científicopedagógica; $c$ ) formação pela articulação entre teoria e prática; e d) formação da vontade pedagógico-política (LINHARES, 1988, p. 76-79).

Uma vez que se toma para a formação docente questões referentes à formação inicial e continuada, relação teoria e prática etc., o objetivo é a formulação de outra lógica para o desenvolvimento do sujeito emancipado por meio da consolidação da base comum nacional na formação docente e de um Sistema Nacional Público de Formação dos Profissionais da Educação. Desta forma será possível garantir que as formas atuais aligeiradas e fragmentadas de formação, baseadas nas NTIC, deem lugar à uma formação em nível superior que contribua para a emancipação humana com vistas à construção de uma nova sociabilidade que não a burguesa.

\section{Considerações finais}

As políticas de formação para o trabalho docente na educação básica que se materializaram no Brasil a partir dos anos de 1990 carregam em si as marcas das orientações dos organismos internacionais como o BM e a UNESCO. Embora o movimento dos educadores, nas mais diferentes representatividades, tenha se colocado criticamente frente à tais medidas, não foi suficiente para evitar que se materializasse no país um tipo de formação fragmentada e aligeirada, possibilitada pelos novos espaços de formação. 
As novas formas de gestão da educação e do trabalho docente baseados no gerencialismo contribuíram não apenas para a fragilizar as políticas de formação para o trabalho docente, mas sobretudo, para a formar um docente de novo tipo com vistas à formar o trabalhador de novo tipo, desde a educação básica, pautado na lógica da empregabilidade. $\mathrm{O}$ resultado foi a proeminência de um tipo de avaliação e certificação das competências que gerou a intensificação, a proletarização e a desprofissionalização do trabalho docente.

A gênesis do reconhecimento do notório saber como possibilidade de realização do trabalho docente na educação básica encontra-se nas teorias da administração, pautadas na "sociedade do conhecimento" e na ideia da "educação ao longo da vida". A base central é a valorização da formação contínua (em serviço) em detrimento da formação inicial (teórica) que será possível por meio das NTIC. Atualmente, no Brasil já existe regulamentação que reconhece o "notório saber" como possibilidade de exercício docente na educação básica, embora não esteja claro quais serão as formas de certificação.

Por fim, apontamos o ensino superior como espaço privilegiado de formação para o trabalho docente na educação básica, por ser o espaço adequado para garantir a indissociabilidade entre a formação prática/teórica, a formação inicial/continuada e pôr fim à lógica da inclusão excludente. Além disso, se constitui no espaço possível de formação do sujeito emancipado, por meio da consolidação da base comum nacional na formação docente e de um Sistema Nacional Público de Formação dos Profissionais da Educação, capaz de contribuir para a formação do sujeito emancipado, capaz de contribuir para a construção de uma sociedade igualitária com uma educação que atenda aos interesses da classe trabalhadora.

\section{REFERÊNCIAS}

ASSOCIAÇÃO COMERCIAL E INDUSTRIAL DE CASCAVEL (ACIC). O quinto pilar da educação. Disponível em: <http://www.acicvel.com.br/noticias/item/6532-oquinto-pilar-da-educacao.html>. Acesso em: 07 jan. 2017.

ASSOCIAÇÃO NACIONAL DE PÓS-GRADUAÇÃO E PESQUISA EM EDUCAÇÃ̃O (ANPED). ASSOCIAÇÃO NACIONAL PELA FORMAÇÃO DOS PROFISSIONAIS DA EDUCAÇÃO (ANFOPE). CENTRO DE ESTUDOS EDUCAÇÃO E SOCIEDADE (CEDES). A Definição das Diretrizes para o Curso de

Pedagogia. Documento enviado ao Conselho Nacional de Educação visando a Elaboração das Diretrizes Curriculares Nacionais para os Cursos de Pedagogia, em 
10/09/2004. Disponível em: <http://www. anped.org. br/200904PosicaoDiretrizsCursos Pedagogia.doc>. Acesso em: 25 jan. 2017.

\section{ASSOCIAÇÃO NACIONAL PELA FORMAÇÃO DOS PROFISSIONAIS DA EDUCAÇÃ O (ANFOPE). Documento Final do XIV Encontro Nacional da ANFOPE. Goiânia (GO), 2008. Mimeografado.}

ALVES, Giovanni. O novo (e precário) mundo do trabalho: reestruturação produtiva e crise do sindicalismo. São Paulo: Boitempo, 2000.

ANTUNES, Ricardo. Os sentidos do trabalho: ensaio sobre a afirmação e a negação do trabalho. 6.ed. São Paulo: Boitempo, 2003.

BERTRAND, Oliver. Avaliação e certificação de competências e qualificações profissionais. Brasília: UNESCO/IIPE, 2005.

BRASIL. Resolução CNE/CP 1, de 18 de fevereiro de 2002. 2002.Institui Diretrizes Curriculares Nacionais para a Formação de Professores da Educação Básica, em nível superior, curso de licenciatura, de graduação plena. Brasília (DF), 2002.

BRASIL. Resolução No 2, de 26 de junho de 1997. 1997. Dispõe sobre os programas especiais de formação pedagógica de docentes para as disciplinas do currículo do ensino fundamental, do ensino médio e da educação profissional em nível médio. Disponível em: <http://portal.mec.gov.br/setec/arquivos/pdf/Res02.pdf>. Acesso em: 07 jan. 2017.

BRASIL. Resolução No 4, de 13 de julho de 2010. 2010. Define Diretrizes

Curriculares Nacionais Gerais para a Educação Básica. Disponível em:

<http://portal.mec.gov.br/ dmdocuments/ rceb004_10.pdf>. Acesso em: 21 jan. 2017.

BRASIL. Constituição da República Federativa do Brasil de 1988. Brasília, 5 de outubro de 1988.

BRASIL. Decreto No 6.755, de 29 de janeiro de 2009. 2009. Institui a Política Nacional de Formação de Profissionais do Magistério da Educação Básica, disciplina a atuação da Coordenação de Aperfeiçoamento de Pessoal de Nível Superior -CAPES no fomento a programas de formação inicial e continuada, e dá outras providências. Publicado no DOU de 30.01.2009. Disponível em: http://www.planalto.gov.br/ ccivil_03/_Ato20072010/ 2009/Decreto/D6755.htm. Acesso em: 25 fev. 2017.

BRASIL. Lei $\mathbf{N}^{\mathbf{0}}$ 12.014, de 6 de agosto de 2009. 2009. Altera o art. 61 da Lei no 9.394, de 20 de dezembro de 1996, com a finalidade de discriminar as categorias de trabalhadores que se devem considerar profissionais da educação. Disponível em: <https://www.planalto.gov.br/ccivil_03/_Ato2007-2010/2009/Lei/L12014.htm>. Acesso em: 22 jan. 2017.

BRASIL. Lei $\mathbf{N}^{\mathbf{0}} \mathbf{1 3 . 4 1 5}$, de 16 de fevereiro de 2017. Altera as Leis nos 9.394, de 20 de dezembro de 1996, que estabelece as diretrizes e bases da educação nacional, e 11.494, de 20 de junho 2007, que regulamenta o Fundo de Manutenção e Desenvolvimento da Educação Básica e de Valorização dos Profissionais da Educação, a Consolidação das Leis do Trabalho - CLT, aprovada pelo Decreto-Lei no 5.452, de 1o de maio de 1943, e 
o Decreto-Lei no 236, de 28 de fevereiro de 1967; revoga a Lei no 11.161, de 5 de agosto de 2005; e institui a Política de Fomento à Implementação de Escolas de Ensino Médio em Tempo Integral. Disponível em: <http:// www.

planalto.gov.br/ccivil_03/_Ato2015-2018/2017/Lei/L13415. htm>. Acesso em: 12 mar. 2017.

BRASIL. Lei No 9394, de 20 de dezembro de 1996. Lei de Diretrizes e Bases da Educação Nacional. Brasília, 1996.

CIAVATTA, Maria. O mundo do trabalho em imagens. Rio de Janeiro: DP\&A, 2002.

DELORS, Jacques (Org.). Educação um tesouro a descobrir: Relatório da UNESCO da Comissão Internacional sobre Educação para o Século XXI (1996). 6.ed.. São Paulo: Cortez; Brasília: MEC: UNESCO, 2001.

DRUCKER, Peter. Administrando em tempos de grandes mudanças. Tradução de Nivaldo Montigelli Júnior. São Paulo: Pioneira, 1995.

DRUCKER, Peter . A sociedade pós-capitalista. Tradução de Nivaldo Montingelli Júnior. 2. ed. São Paulo: Pioneira, 1994.

ENSINA BRASIL. Quem buscamos. Disponível em: <http:// www. ensinabrasil. org/sejaumensina/>. Acesso em: 18 abr. 2017.

ENSINA BRASIL. Seja um ensina. Disponível em: <http://www. ensinabrasil. org/ sejaumensina/>. Acesso em: 18 abr. 2017.

FERNANDES, Florestan. A revolução burguesa no Brasil: ensaio de interpretação sociológica. 5.ed. São Paulo: Globo, 2006.

FREITAS, Helena Costa Lopes de. A Reforma do Ensino Superior no Campo da Formação dos Profissionais da Educação Básica: as políticas educacionais e o movimento dos educadores. Educação e Sociedade, Campinas (SP), v. 20, n. 68 [número especial], p. 17-44, 2000.

FRIGOTTO, Gaudêncio. Reformas educativas e o retrocesso democrático no Brasil nos anos 90. In: LINHARES, Célia (Org.). Os professores e a reinvenção da escola: Brasil e Espanha. São Paulo: Cortez, 2001, p. 57-80.

GRAMSCI, Antonio. Os Intelectuais e a organização da cultura. 8.ed.. Tradução de Carlos Nelson Coutinho. Rio de Janeiro: Civilização Brasileira, 1991.

KOSIK, Karel. Dialética do concreto. Tradução de Célia Neves e Alderico Toríbio. Rio de Janeiro: Paz e Terra, 1969.

LIMA, Kátia Regina de Souza. Contra-reforma na educação superior: de FHC a Lula. São Paulo: Xamã, 2007. 206p.

LINHARES, Célia Frazão Soares. A escola e seus profissionais: tradições e contradições. Rio de Janeiro: Agir, 1988. 
MACEDO, Jussara Marques de. A mundialização do capital e seus reflexos nas políticas de formação de professores no período 1990-2010. 2011. 2 v. 494 f. Tese (Doutorado em Educação) - Universidade Federal Fluminense, Niterói, RJ, 2011.

MACEDO, Jussara Marques de Reestruturação produtiva e políticas de formação de novas competências para o trabalho docente. In: Reunião Anual da ANPEd, XXV, Caxambu (MG), Set./Out/2002. Anais. Caxambu (MG): Microservice, 2002. CD-Rom.

MACEDO, Jussara Marques de; LAMOSA, Rodrigo. A regulação do trabalho docente no contexto da reforma gerencial da educação. Revista Contemporânea de Educação, vol. 10, n. 20, p. 133-152, julho/dezembro, 2015.

MELLO, Guiomar Namo de. Cidadania e competitividade: desafios educacionais do terceiro milênio. 10.ed. São Paulo: Cortez, 2005.

MELLO, Guiomar Namo de. Formação inicial de professores para a educação básica: uma (re)visão radical. São Paulo em Perspectiva, São Paulo, vol. 14, n. 1, p. 98-110, jan./mar., 2000.

MÉSZÁROS, István. A educação para além do capital. 2.ed. Tradução de Isa Tavares. São Paulo: Boitempo, 2008.

\section{ORGANIZAÇÃO PARA A COOPERAÇÃO E DESENVOLVIMENTO}

ECONÔMICO (OCDE). Professores são importantes: atraindo, desenvolvendo e retendo professores eficazes. São Paulo: 2006.

OLIVEIRA, Dalila Andrade. Política educacional nos anos 1990: educação básica e empregabilidade. In: DOURADO, Luiz Fernandes; PARO, Vitor Henrique (Orgs.). Políticas públicas e educação básica. São Paulo: Xamã, 2001. p. 105-121.

OTRANTO, Célia Regina. A Universidade Rural e a discussão sobre os Institutos Superiores de Educação. In: SOUZA, Donaldo Bello; CARINO, Jonaedson (Orgs.). Pedagogo ou professor? O processo de reestruturação dos cursos de educação no Rio de Janeiro. Rio de Janeiro: Quartet, 1999, p. 69-79.

SCHULTZ, Theodore W. O capital humano: investimentos em educação e pesquisa. Tradução de Marco Aurélio de Moura Matos. Rio de Janeiro: Zahar. 1973.

SHIROMA, Eneida Oto. Implicações da Política de Profissionalização sobre a Gestão e o Trabalho Docente. In: II Simpósio sobre Trabalho e Educação. NETE. Faculdade de Educação da UFMG, nov. 2004.

SOUZA, José dos Santos. Desafios do trabalho docente nos Institutos Federais de Educação, Ciência e Tecnologia Brasileiros. In: MAUÉS, Olgaíses Cabral et al. Expansão da educação superior: formação e trabalho docente. Belo Horizonte (MG): Fino Traço, 2015. pp. 65-85.

TEACH FOR ALL. Teach For All. Disponível em: <http://teachforall.org/en>. Acesso em: 03 abr. 2017. 
VAILLANT, Denise. A Profissão Docente. In: SCHWARTZMAN, Simon; COX, Cristián (Editores). Políticas educacionais e coesão social: uma agenda latinoamericana. Tradução de Micheline Christophe e Roberta Caldas. Rio de Janeiro: Elsevier; São Paulo: IFCH, 2009, p. 126-169.

\section{Como referenciar este artigo}

MACEDO, Jussara Marques de. Reconhecimento do notório saber e a inclusão excludente do professor na educação básica: qual o lugar da universidade na formação? Revista on line de Política e Gestão Educacional, Araraquara, v. 21, n. esp.2, p. 12391259, nov. 2017. Disponível em: <http://dx.doi.org/10.22633/rpge.v21.n.esp2.2017.10841>. E-ISSN:1519-9029.

Submetido em: 28/07/2017

Aprovado em: 30/09/2017 